\title{
Strength and interface failure mechanism of adhesive joints
}

\author{
Wei $\mathrm{Xu}^{*}$, Yueguang Wei \\ State key Laboratory of Nonlinear Mechanics, Institute of Mechanics, Chinese Academy of Sciences, Beijing 100190, PR China
}

\section{A R T I C L E I N F O}

\section{Article history:}

Accepted 14 November 2011

Available online 31 December 2011

\section{Keywords:}

Interface

Finite element analysis

Mechanical properties of adhesive

Cohesive zone model

\begin{abstract}
A B S T R A C T
Adhesive joints have a wide range of applications in the civil engineering, automotive and aircraft industries. In the present research, we use the finite element method to systematically study the overall strength and interface failure mechanism of single lap joints, which are subjected to tensile loading, focusing on the effects of various system parameters including fracture energy of the adhesive layer, overlap length and adhesive layer thickness on the load-bearing capability of the joints. The results show that the overlap length and the adhesive fracture energy have combined influences on the load-bearing capability. On the other hand, a preliminary damage analysis of the adhesive layer is carried out, considering the situations when the loads arrive to the peak values. Furthermore, the interface behavior is investigated, including the interface stress analysis and interface slip. The rotation of the joint during loading and its influence factors are studied as well. Obtained results suggest that the interface stress distributions are related to the slip and the rotation angle. Crown Copyright $\odot 2011$ Published by Elsevier Ltd. All rights reserved.
\end{abstract}

\section{Introduction}

Adhesive bonding is a method used to achieve a connection and immobilization. Compared with the traditional mechanical assembly technologies (e.g., bolted, pinned, or riveted methods), it has a lot of advantages. First of all, nearly all the types of materials, including some non-metals, can be bonded by adhesives. Under some conditions, adhesive bonding is the only possible method to adopt, such as thin-walled sections. Secondly, the adhesive bonding technology makes the bonded structures light in comparison with other assembly technologies (e.g., mechanical fasteners). Thirdly, due to the characteristic of making no holes in surfaces prior to bonding, stress concentration in the bonded joints can be decreased than when caused by other means of jointing such as bolted and rivet joints. As the most common type of adhesive bonding joints, the single lap joint (SLJ) shown in Fig. 1a has the advantages described above. Moreover, single lap joints are economical, practical and easy to make $[1,2]$. Thus they have been found increasingly wide applications in many industries, such as civil engineering [3-5], automotive [6-8] and aircraft industries [9].

Previous researches focused on improving the strength of the joints, and some techniques were therefore developed in order to realize the goal. Some researches presented the surface treatments on the overlap area before bonding [10-12]. Others showed the enhanced adhesive strength by modifying the shape $[13,14]$ of the joints and adding the fillets at the overlap extremities [15]. Most researches including numerical [13-18] and analytical studies [19-22] presented the stress distributions along the bondline

\footnotetext{
* Corresponding author. Tel.: +86 10 82543954; fax: +86 1062561284 .

E-mail address: xuwei@Inm.imech.ac.cn (W. Xu).
}

(interface) between the adherents for the purpose of optimizing and designing a high-quality interface, and several methods were proposed accordingly. The load-bearing capabilities of joints changed negligibly with a certain length of gaps in the adhesive layers [23-25]. Additionally, the relationship between the stress distributions and the types of the adhesive layers with various thicknesses was presented numerically and experimentally $[2,12,26]$.

Although the mechanical behaviors of adhesive joints have been investigated by a lot of researchers as mentioned above, the understanding to the strength and failure mechanisms of joints is still local and rough due to the complexity of mechanical behaviors of adhesive joints subjected to loading. Therefore, it is necessary to carry out the systematical research on the mechanical behaviors of adhesive joints. In the present research, a numerical model utilizing finite elements method (FEM) is established to describe the mechanical behaviors of the single lap joints subjected to tensile loading. Our attention will focus on the effects of various system parameters including fracture energy of the adhesive layer, overlap length and adhesive layer thickness on the load-bearing capability of the joint. On the other hand, since the interface behavior is vital for the load-bearing capacity, interface failure mechanism is therefore studied in order to describe the failure of the joints. In addition, the rotation of the joints during loading and its influence on the joint mechanical behavior is investigated.

\section{Model and simulation}

In this section, a numerical model of the single lap joint is built with the commercially available FEM code ABAQUS. Since the width of the adherends used for the joint is far larger than their 
a

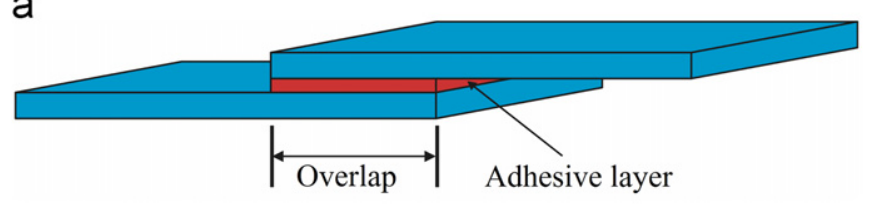

b

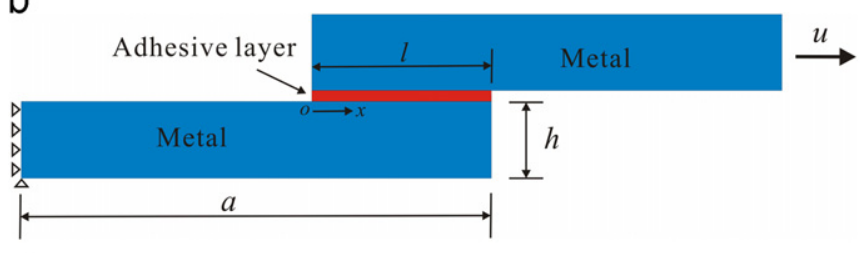

C

Fig. 1. (a) Configuration of single lap joint; (b) numerical model of the adhesive joint and (c) its finite element mesh.

thickness, adhesive joints under tension can be simplified as the elastic-plastic plane strain problems.

\subsection{Computational model}

Fig. 1b depicts the computational model of the single lap joint, which consists of two same metallic adherends with the thickness of $h$, having a typical value of $3 \mathrm{~mm}$. The length of the adherends $a$, is assigned the value of $120 \mathrm{~mm}$. The adherends are connected by the adhesive layer with the length of $l$, which is also called overlap length in the paper. The adherends are meshed using four-node quadrilateral plane strain elements, of which the total number is set as 2240 upon checking the convergence of the numerical results. Under uniaxial stretching, the joint is taken to deform under plane strain. In the numerical model, the left side of the joint is fixed in the horizontal direction, and the lower left corner is also fixed in the vertical direction. The model is loaded by the means of increasing displacement, and a uniform displacement of $u$ is applied to the right side of the joint.

The metallic adherends are modeled as elastic-plastic solids, with their true stress-strain curves fitted using power-law hardening laws [27], as:

$\sigma= \begin{cases}E \varepsilon & \varepsilon \leq \sigma^{\mathrm{Y}} / E \\ \sigma^{\mathrm{Y}}\left(\frac{\varepsilon}{\sigma^{\mathrm{Y}} / E}\right)^{N} & \varepsilon>\sigma^{\mathrm{Y}} / E\end{cases}$

where $E$ is the Young's modulus, $N$ is the strain hardening exponent, and $\sigma^{\mathrm{Y}}$ is the yield strength. For the present model, these three material properties are $70 \mathrm{GPa}, 0.02$ and $275 \mathrm{MPa}$, respectively, taken from Ref. [28].

In the present simulation, since the model of SLJ would potentially undergo large displacement and large rotation in the overlap region, the geometrical nonlinearity has been hence considered when the computation is implemented.

\subsection{Cohesive zone model}

Cohesive zone models (CZMs) based on traction-separation laws are well suitable to describe the decohesion in composite structures. The CZMs require traction-separation (T-S) relations for characterizing the constitutive laws of them. So far, considerable researches have focused on the constitutive laws of CZMs and their applications [29]. It has been established that whilst the peak value and area of the T-S curve are vital for capturing the interface separation behavior, its precise shape is of less significance [30]. Consequently, for simplicity, the bilinear T-S law $[29,31,32]$ shown in Fig. 2 is selected for the present study. Built upon the bilinear cohesive zone model (CZM), the adhesive layer, also treated as interface between the two metallic adherends, is modeled with the cohesive zone elements.

Fig. 2 presents the traction-separation (T-S) relation of the CZM, with Fig. 2a and b representing the relations in normal and shear direction, respectively. To distinguish the tensile T-S law from the shear one, let the superscript " $n$ " represent the normal direction and " $\mathrm{s}$ " denote the shear direction. In Fig. 2, $u_{\mathrm{m}}$ and $u_{\mathrm{c}}$ are the maximum and critical separation, respectively, and $T$ is the traction stress.

Since the maximum value of $T^{\mathrm{n}}$ is $\sigma_{\mathrm{m}}$ while that of $\left|T^{\mathrm{s}}\right|$ is $\tau_{\mathrm{m}}$, the interfacial fracture energies in the two directions can be expressed as:

$$
\begin{aligned}
& \Gamma^{\mathrm{n}}=\int_{0}^{u_{\mathrm{m}}^{\mathrm{n}}} T^{\mathrm{n}} \mathrm{d} u^{\mathrm{n}}=\frac{1}{2} \sigma_{m} u_{\mathrm{m}}^{\mathrm{n}} \\
& \Gamma^{\mathrm{s}}=\int_{0}^{u_{\mathrm{m}}^{\mathrm{s}}} T^{\mathrm{s}} \mathrm{d} u^{\mathrm{s}}=\frac{1}{2} \tau_{m} u_{\mathrm{m}}^{\mathrm{s}}
\end{aligned}
$$

As the loading is increased beyond a critical value, the interface begins to soften, and degrade, namely, the interface is now in the damaged (or softening) state. Typically, damage is initiated when a certain criterion is satisfied. In the present study, inspired by the bilinear law of Fig. 2, the quadratic nominal stress criterion is adopted to characterize the interfacial damage, described as:

$\left(\frac{\left\langle T^{n}\right\rangle}{\sigma_{m}}\right)^{2}+\left(\frac{T^{s}}{\tau_{m}}\right)^{2}=1$

where \langle\rangle represents the Macaulay bracket defined by $\langle x\rangle=1 / 2(x+|x|)$, with the usual interpretation that a pure compressive deformation or stress state does not initiate damage.

It is assumed that interfacial damage occurs when Eq. (3) is satisfied and a single damage variable $D$ based on the total displacement jump $\Delta$ is introduced (i.e., $\Delta=\sqrt{\left\langle u^{\mathrm{n}}\right\rangle^{2}+\left(u^{\mathrm{s}}\right)^{2}}$ ) [33,34], as:

$D=\frac{\Delta_{\mathrm{f}}\left(\Delta_{\max }-\Delta_{\mathrm{c}}\right)}{\Delta_{\max }\left(\Delta_{\mathrm{f}}-\Delta_{\mathrm{c}}\right)}$

where $\Delta_{\mathrm{c}}$ and $\Delta_{\mathrm{f}}$ denote the total displacement at damage initiation and complete failure. $\Delta_{\mathrm{f}}$ is determined by $\Delta_{\mathrm{f}}=2 \Gamma / T_{\mathrm{c}}^{\text {eff }}$ with $T_{\mathrm{c}}^{\mathrm{eff}}$ as the effective traction at damage initiation (i.e., $T_{\mathrm{c}}^{\mathrm{eff}}=\sqrt{\left(T_{\mathrm{c}}^{\mathrm{n}}\right)^{2}+\left(T_{\mathrm{c}}^{\mathrm{s}}\right)^{2}}$. In Eq. (4), $\Delta_{\max }$ denotes the maximum total displacement ever experienced during the loading history.

Noting that $\Gamma$ is the total fracture energy of the adhesive, it can be also called the adhesive fracture energy. Generally, $\Gamma$ depends

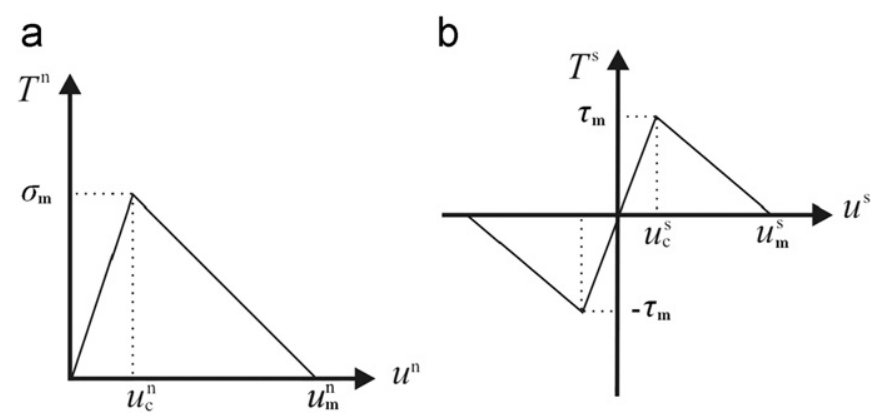

Fig. 2. Typical bilinear traction-separation law of cohesive zone model: (a) tractionseparation relation in tension; and (b) traction-separation relation in shear. 
on the mode-mixity. In other words, the adhesive fracture energy varies as a function of the mode-mixity. Thus it could be termed the mixed-mode fracture energy. In the present investigation, $\Gamma$ could be determined by the linear fracture criterion, which could be expressed as,

$\frac{G^{\mathrm{n}}}{\Gamma^{\mathrm{n}}}+\frac{G^{\mathrm{s}}}{\Gamma^{\mathrm{s}}}=1$

where $G^{\mathrm{n}}$ and $G^{\mathrm{s}}$ denote work done by the traction and its conjugate relative displacement in the normal and shear direction, respectively. $\Gamma^{\mathrm{n}}$ and $\Gamma^{\mathrm{s}}$ refer to the critical fracture energies required to cause failure in the normal and shear direction, respectively, with the definition in Eq. (2). Consequently, the total adhesive fracture energy could be determined by $\Gamma=G^{\mathrm{n}}+G^{\mathrm{s}}$ when Eq. (5) is satisfied. It should be mentioned a major assumption is proposed in the present simulation, namely, $\Gamma^{\mathrm{n}}=\Gamma^{\mathrm{s}}$. By this assumption, the adhesive fracture energy $\Gamma$ doesn't vary with the normal and shear mode-mixity in the present simulation.

It is worth mentioning that the peak traction stresses $\sigma_{\mathrm{m}}$ and $\tau_{\mathrm{m}}$ are termed the separation strengths, which could be regarded having the same values of the yield strength in the present simulation. Furthermore, following the previous research [35], the tensile and shear traction stresses are assumed equal, with the value taken from Ref. [28] (i.e., $\sigma_{\mathrm{m}}=\tau_{\mathrm{m}}=\sigma_{\mathrm{ad}}=8.27 \mathrm{MPa}$ ).

The adhesive layer is modeled with a single layer of four-node cohesive elements, which share nodes with the neighboring elements in the upper and lower metallic adherends. For a purpose of obtaining better computational accuracy, the overlap region is meshed densely while sparse mesh is adopted in other regions as shown in Fig. 1c. The number of cohesive elements is set as 80 for the case with the overlap length of $40 \mathrm{~mm}$.

\section{Load-bearing capacity and damage analysis}

The adhesive joint is loaded in the uniaxial direction, with the load $F$ increasing with the increasing displacement $u$. the adhesive layer would damage when the load increases to a critical value. Then the load would drop due to the damaged adhesive layer. Numerous reports proposed the peak value of load could be employed to estimate the load-bearing capacity of the adhesive joints $[1,2,12,36-39]$. In the present research, the peak load $F_{\mathrm{p}}$ and its influence factors are also considered as follows.

In fact, the peak load may be affected by three categories of system parameters: the first one is about the material factors of adhesive layer, such as the separation strength $\sigma_{\text {ad }}$, adhesive fracture energy $\Gamma$; the second is about the material factors of metallic adherends, such as $E, N$ and $\sigma^{\mathrm{Y}}$; the third is about the geometrical parameters, such as overlap length $l$, adhesive thickness $w$ and size of adherends (i.e., $a$ and $h$ ). The peak load $F_{\mathrm{p}}$ can be expressed by the below function:

$F_{p}=f_{1}(\underbrace{\sigma_{a d}, \Gamma,}_{\text {properties of adhesive }} ; \underbrace{E, N, \sigma^{Y}}_{\text {properties of metal adherend }} ; \underbrace{l, w, a, h}_{\text {geometry }} ; \cdots)$

which can be converted into the normalized form:

$\frac{F_{p}}{\sigma_{a d} h}=f_{2}\left(\frac{\sigma_{a d}}{\sigma^{Y}}, \frac{\Gamma}{\sigma_{a d} h} ; \frac{E}{\sigma^{Y}}, N ; \frac{l}{h}, \frac{w}{h}, \frac{a}{h} ; \cdots\right)$

In this paper, the parameters for the metallic adherends and adhesive separation strength are treated as constant values. Accordingly, the present investigation just considers the influences of the adhesive fracture energy, overlap length and adhesive layer thickness.

\subsection{Process of loading}

Fig. 3 shows the typical load-displacement curve for the present model, with the normalized overlap length of 13.33 and normalized adhesive fracture energy of $40.31 \times 10^{-3}$. To verify the accuracy and applicability of the present model, obtained results using the present model are compared with the existing experimental result from Ref. [38], which studied the strength of aluminum single lap joints bonded by the epoxy adhesive. To facilitate the comparison, the load and displacement are both normalized by the related material and geometrical parameters. Overall, the present computational result agrees with the experimental measurement. However, it should be noted that the peak load of the computational result is a little lower than that of experimental measurement, which may be caused by the assignment of separation strength of adhesive in the present model. Strictly speaking, the separation strength of adhesive is larger than its yield strength in practice [27], but the exact relation between the separation strength and yield strength is still uncertain. Accordingly, the assumption of the separation strength being equal to yield strength is adopted following the previous research [28]. Since the peak load from the simulation based on this assumption would be a little lower than practice, it suggests that the engineering designs from the present simulation are helpful to use of safety, with ensuring the calculation reasonable.

Next, Fig. 4 shows the normalized load-displacement curves for the different adhesive fracture energies of the adhesive layer, considering the four overlap lengths, which are depicted in Fig. 4a-d, respectively. In Fig. 4, the entire curves exhibit linear rising up at the beginning, which can be seen as the first stage of the deformation. In this stage, nearly all the curves in a figure appear same slope, which means the influence of the adhesive fracture energy on the so-called stiffness of the joint can be neglected.

However, the curves drop down after the loads arrive to some critical values, which are the peak loads. It is worth mentioning that the drop trend is affected by the adhesive fracture energy. As depicted in Fig. 4a, the curves drop to zero dramatically for the relatively low normalized adhesive fracture energies (i.e., $2.42 \times 10^{-3}, 4.03 \times 10^{-3}$ and $8.06 \times 10^{-3}$ ), by contrast, the curves drop slowly for the relatively high normalized adhesive energies (i.e., $40.31 \times 10^{-3}, 80.61 \times 10^{-3}$ and $120.92 \times 10^{-3}$ ). It should be noted that the displacement $u$ in Fig. 4 is defined as the horizontal

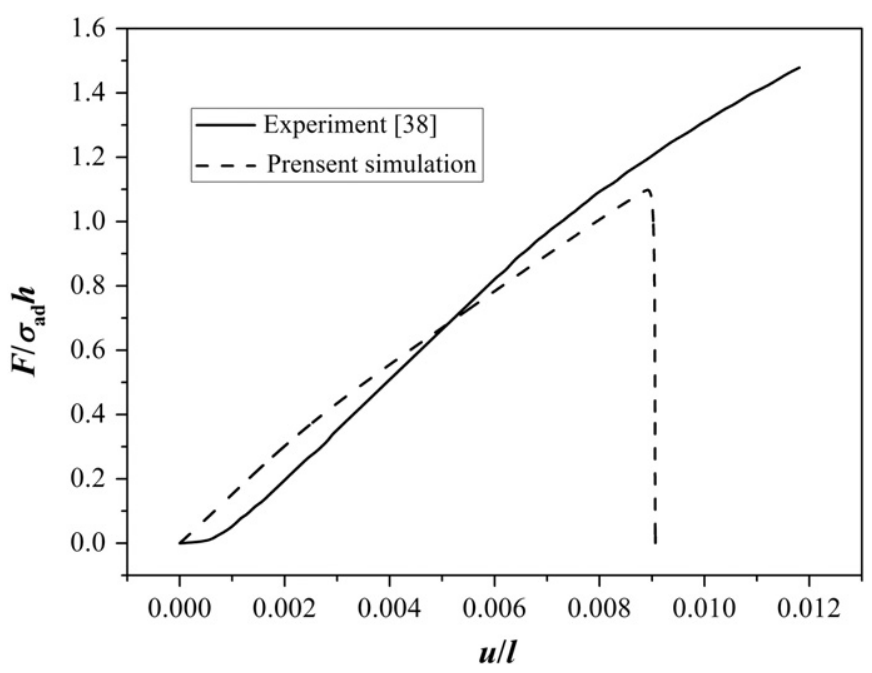

Fig. 3. Normalized load plotted as a function of normalized displacement: comparison between the present model prediction with the experimental measurement [38]. 

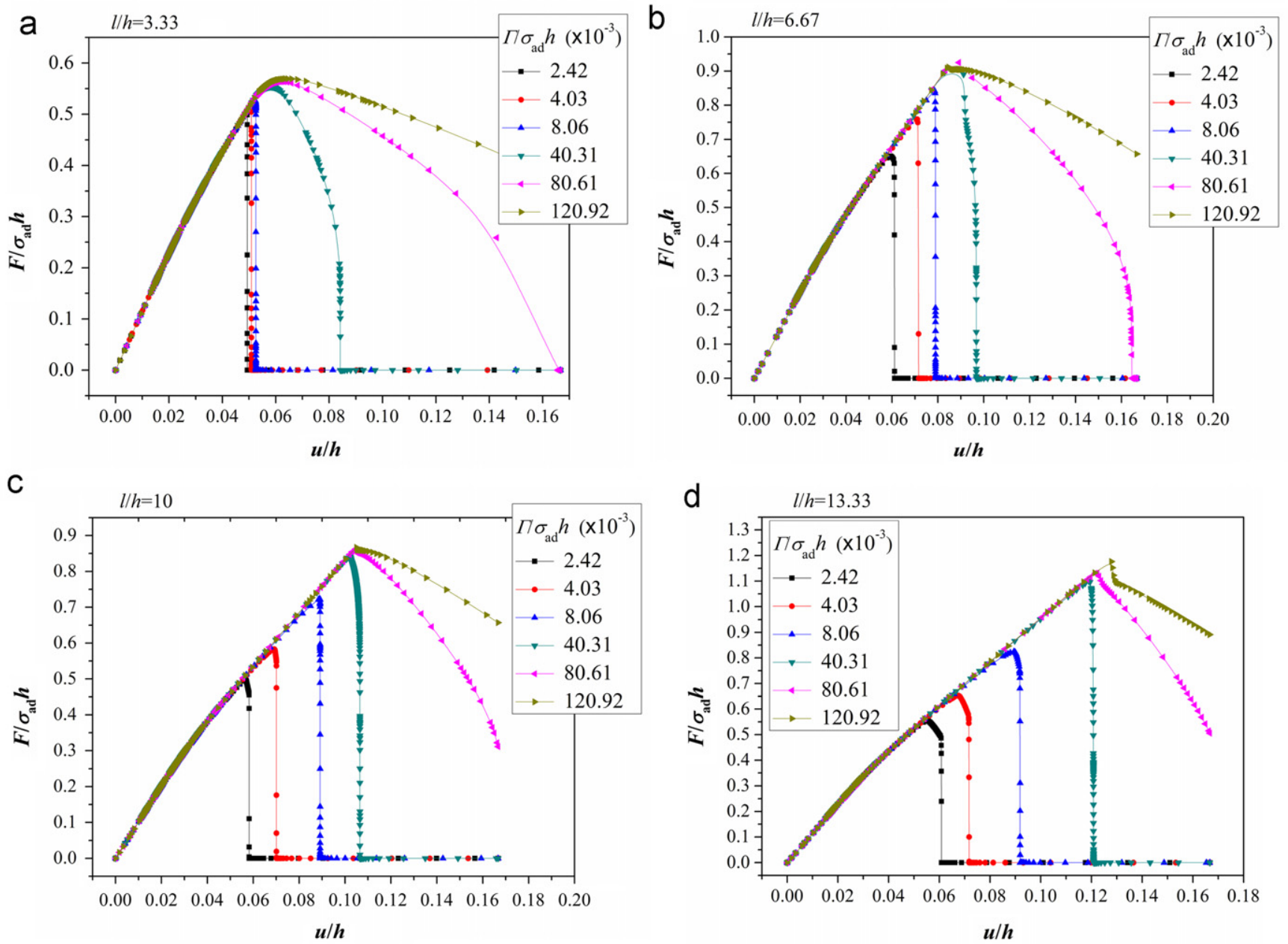

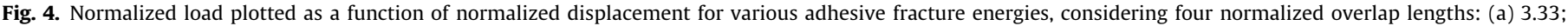
(b) 6.67 ; (c) 10 and (d) 13.33 .

projection of the displacement of right end in the specimen. Since the specimen would rotate when loaded, the displacement $u$ is not identical to the total displacement of the right end. The detailed analysis on the rotation of the specimen will be presented later in Section 4.3.

\subsection{Effect of adhesive fracture energy}

When the cohesive zone model is employed to describe the interface separation behavior, separation strength and fracture energy are two vital parameters, which would influence the loadbearing capacity of the adhesive joints together. Among them, the influences of the adhesive separation strength have been investigated by some experimental and numerical researches $[36,37,39,40]$. It is apparent and understandable that increasing the adhesive separation strength would enhance the load-bearing capacity substantially. Some researches have even concluded that the separation strength is more sensitive for the interface behavior than the fracture energy [37, 39, 40]. In other words, increasing the separation strength of adhesive would be more profound for improving interface bonding. Nevertheless, the effects of the adhesive fracture energy are still in controversy. This section separately presents the effects of the adhesive fracture energy under the condition of unchanged adhesive separation strength.

In the present study, the displacement corresponding to the peak load in Fig. 4 is defined as critical displacement $u_{\mathrm{c}}$.
Fig. 5a and b, respectively plot the peak load and critical displacement as the functions of adhesive fracture energies for selected overlap lengths, which exhibit the similar trends. Both the peak load and critical displacement rise up sharply at the initial stage, however, with the increasing adhesive fracture energy, the rise trend continues to slow down, until to stable. It can be found that increasing the adhesive fracture energy (i.e., increasing the toughness of adhesive layer) plays an important role in enhancing the load-bearing capacity of the adhesive joint. However, when the toughness increases to some level, the effect of the toughness on the load-bearing capacity appears more and more unobvious. The above results would be explained from the view of damage analysis, which will be presented later in Section 3.5.

\subsection{Effect of overlap length}

The load-displacement curves depicted in Fig. 4 correspond to four selected overlap lengths. It can be found that they have apparent discrepancy. In order to describe the effect of the overlap length, Fig. 6a shows the relationship between the normalized peak load and the overlap length, of which consist the situations for the brittle and ductile adhesive layers, corresponding to the normalized adhesive fracture energy of 0.0024 and 0.121 , respectively. The Fig. 6a suggests the influence of increasing the overlap length on enhancing the load-bearing capability is negligible for the brittle adhesive layer, while increasing the overlap length can substantially 
a

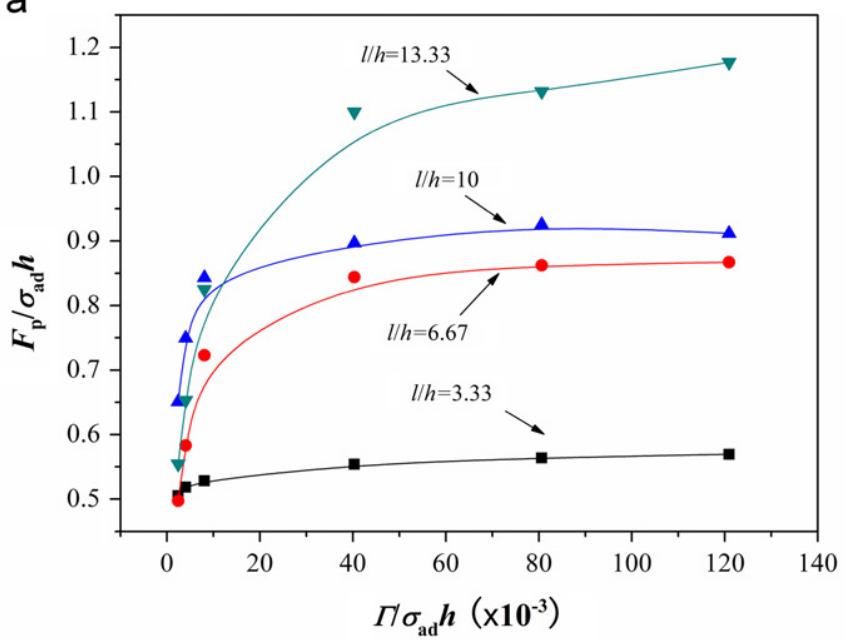

b

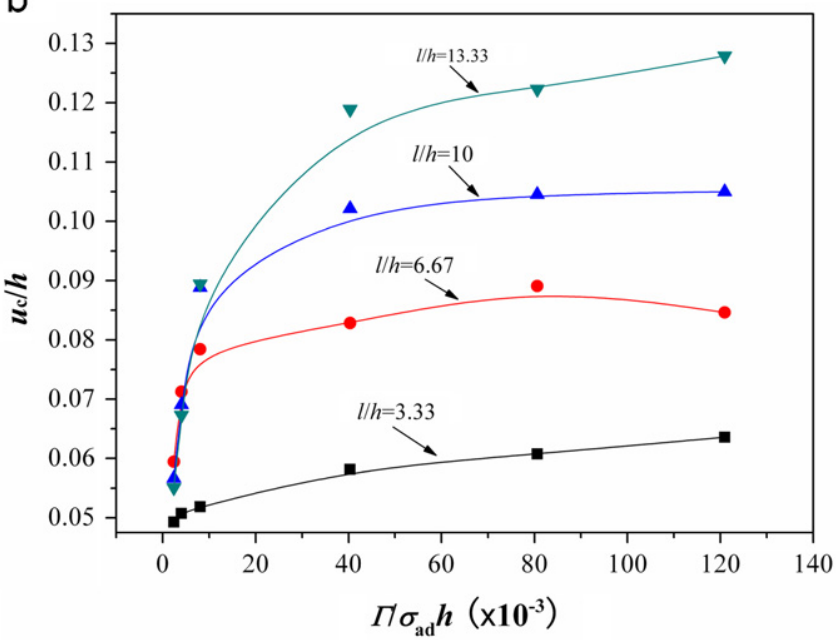

Fig. 5. (a) Normalized peak load and (b) Critical displacement plotted as functions of normalized adhesive fracture energies.

enhance load-bearing capability for the ductile adhesive layer. Besides, Fig. 6a plots the difference between the peak loads corresponding to the two adhesive layers (i.e., $\Delta F_{\mathrm{p}} / \sigma_{\mathrm{ad}} h$ ), which increases with the increasing overlap. It suggests the ascendancy of the ductile adhesive layer comparing with the brittle one is increasingly prominent with the increasing overlap length. Moreover, increasing the overlap length can make full use of the loadbearing capacity for the ductile adhesive layer; on the contrary, increasing the overlap length affects the load-bearing capacity for the brittle adhesive layer negligibly.

Recently, large numbers of researches defined the adhesive joint strength $\left(\sigma_{\mathrm{p}}\right)$ by the ratio between the peak load $F_{\mathrm{p}}$ and overlap area (especially, overlap length $l$ in plane problem) as the assessment value of the adhesive property $[1,2,12,36-39]$. This paper follows the way and plots the normalized adhesive joint strength as the function of overlap length for various adhesive fracture energies. As shown in Fig. 6b, the normalized ratio continues to decrease with the increasing overlap length. In addition, Fig. 6b suggests that the curves for the larger adhesive fracture energy exhibits higher adhesive joint strength, which is consistent with the results of Section 3.2.

\subsection{Effect of adhesive layer thickness}

Generally, the adhesive layer thickness could influence the adhesive performance in the joint as the following analysis. a

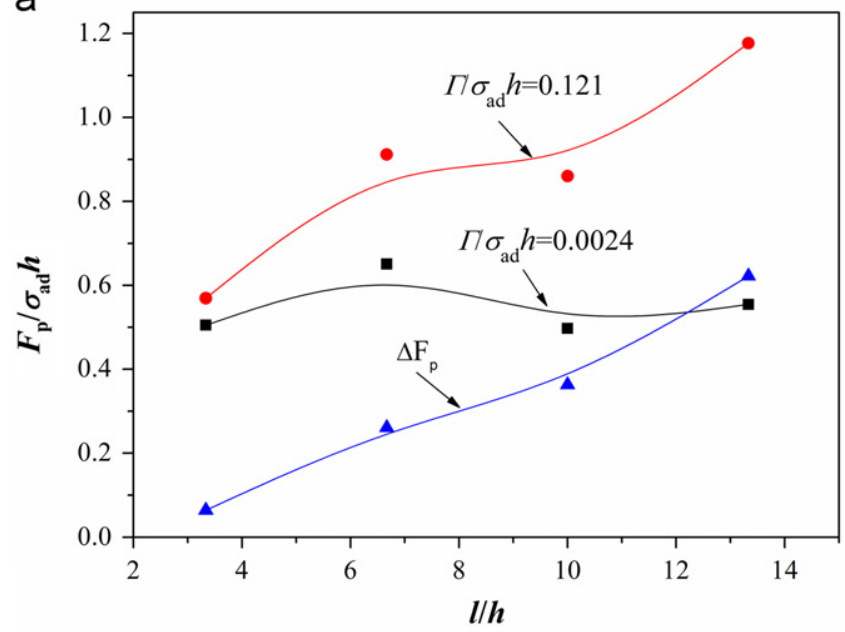

b

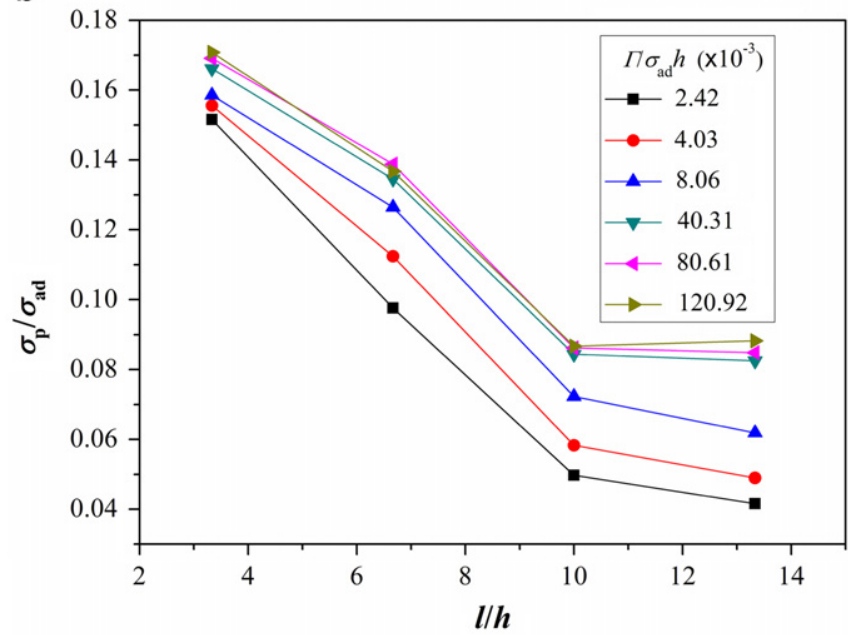

Fig. 6. (a) The relation between the normalized load and overlap length, taking two adhesive energies into account; (b) normalized adhesive joint strength plotted as a function of overlap length for various adhesive energies.

As depicted in Fig. 7a, the adhesive layer with the thickness of $w$, would dissipate two types of energies, including the cohesive energy $\Gamma_{\mathrm{o}}$ and plastic dissipation energy $\Gamma_{\mathrm{p}}$, which denote the energy making the adhesive layer separated and the energy dissipated during the plastic deformation, respectively. In the present investigation, the adhesive fracture energy $\Gamma$ can be replaced by the aforementioned energies equivalently in the below form (see, Fig. 7b):

$\Gamma=\Gamma_{\mathrm{o}}+\Gamma_{\mathrm{p}}$

It can be computed by integrating the work density far downstream along the adhesive layer thickness [27], which is,

$\Gamma_{\mathrm{p}}=\int_{0}^{w}\left(\int_{0}^{\varepsilon_{i j}^{D}} \sigma_{i j} d \varepsilon_{i j}\right) d y$

where $\varepsilon_{i j}^{\mathrm{D}}$ is strain components at the downstream adhesive layer, integration " $\mathrm{d} y$ " is along the thickness of the adhesive layer. This paper assumes that a full damage process takes place in the adhesive layer, following the similar work [40], $\Gamma_{\mathrm{p}}$ can be estimated approximately by:

$\Gamma_{\mathrm{p}} \approx w A_{c}$

where $A_{\mathrm{c}}$ is the area below the stress-strain curve of the adhesive material (i.e., epoxy). According to the test data taken from [40], 
a

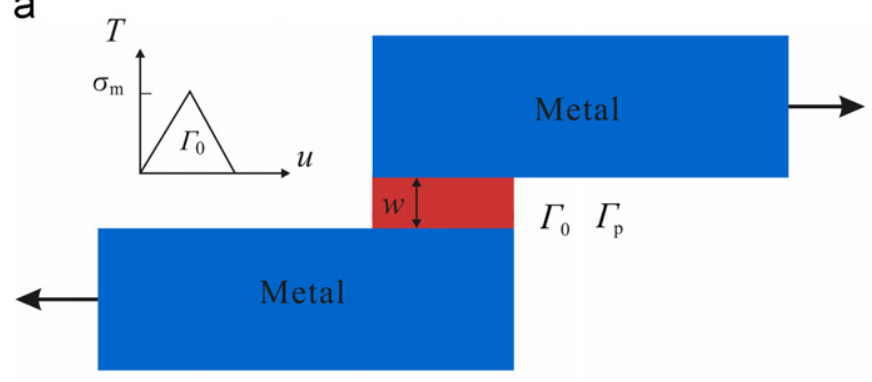

b

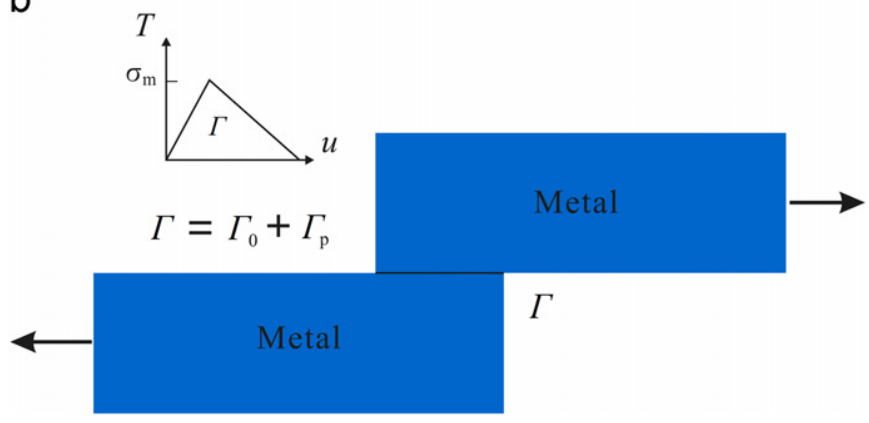

Fig. 7. The adhesive joint with a adhesive layer (a) can be equivalent to a case without adhesive between the upper and lower adherends (b).

$A_{\mathrm{c}}=1.78 \times 10^{6} \mathrm{~N} / \mathrm{m}^{2}$, and the cohesive energy of the adhesive layer $\Gamma_{\mathrm{o}}$ is $110 \mathrm{~J} / \mathrm{m}^{2}$ in the present model.

Fig. 8a plots the load-displacement curves for the various thicknesses of the adhesive layer, of which the normalized overlap length is 13.33 . It can be shown in this figure that all the curves performance similarly at the first stage, then drop drastically to zero after the loads arrive to peak. It is depicted more clearly in Fig. 8b plotting the normalized peak load as a function of the adhesive layer thickness, which exhibits that the peak load rises up with the increasing thickness of the adhesive layer, however, the rise trend becomes slow down.

\subsection{Damage analysis of adhesive layer}

Note that all the loads increase to the peak loads and then decline with the increasing displacements in Fig. 4. Thus it is still questionable what happens to the adhesive layer when the load arrives to peak. In order to find reasonable answer, the damage analysis of the adhesive layer should be carried out considering the situations when the loads arrive to peaks.

Eq. (4) is employed to describe the damage level of the cohesive elements. The damage variable $D$ increases monotonically from 0 (corresponding to damage initiation) to 1 (corresponding to complete failure). Fig. 9a plots the damage distribution along the adhesive layer for the normalized adhesive fracture energy of 0.0024 , with horizontal axis denoting the position coordinate initiated at the left point "o" (see, Fig. 9). It can be found that the damage occurs in the regions near the both extremities of the adhesive layer, while there is no damage in the mid-region. It implies that the adhesive layer in the mid-region doesn't reach to the separation strength.

The damage level can be assessed by the ratio between the damaged and entire adhesive layer lengths. Fig. $9 \mathrm{~b}$ plots the ratio as a function of the various adhesive fracture energies. As a result, the ratio continues to increase as the adhesive fracture energy is increased. The result suggests that, when the loads arrive to peaks, the adhesive layer damage level is lower for the smaller adhesive fracture energy while the adhesive layer damage level is higher for the larger adhesive fracture energy. It can be concluded

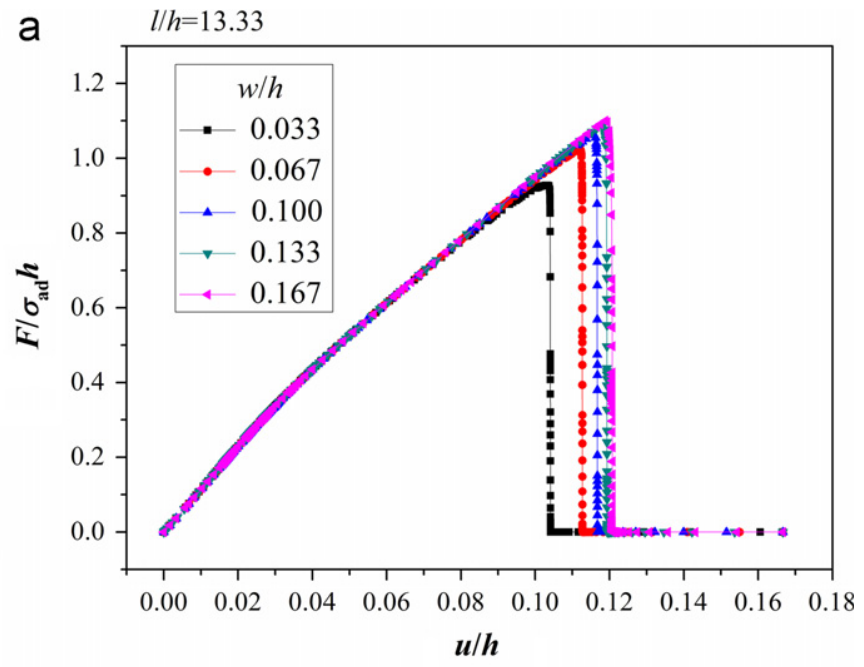

b

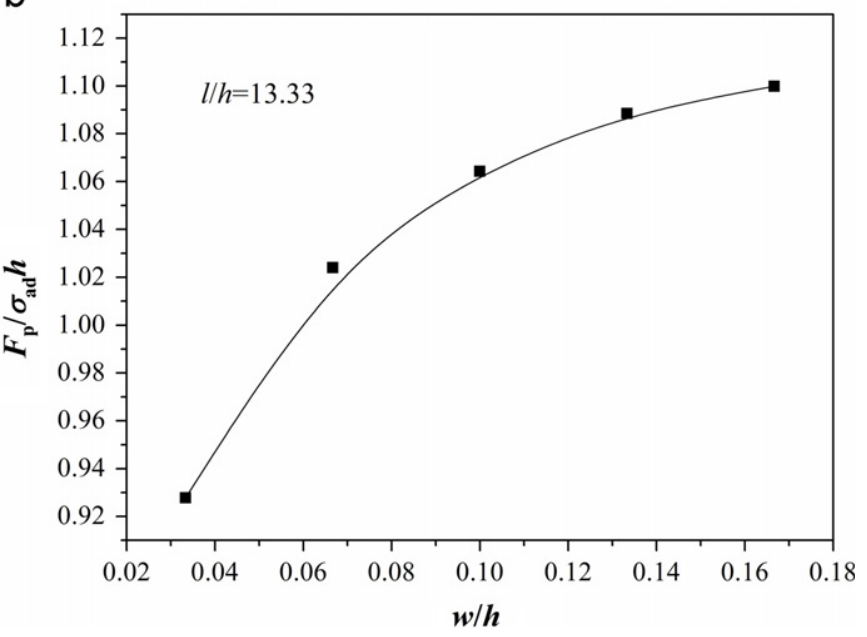

Fig. 8. (a) Load-displacement curves for selected thicknesses of the adhesive layer with the normalized overlap length of 13.33 and (b) normalized peak load plotted as a function of thicknesses of the adhesive layer.

that the load-bearing capacity of the whole adhesive layer can be made full use of in the case of the larger adhesive energies.

Based on the above results, accordingly, it could be understood that the peak load rises up with the increasing adhesive fracture energy at the initial stage of Fig. 5a. However, as the adhesive fracture energy is increased further, the damage level of the adhesive layer attain to saturation, which means the whole adhesive layer has been made full use of. After that, increasing the adhesive fracture energy further would just increase the energy dissipation during interface softening. Consequently, the adhesive joints present a ductile failure mode with the peak load varying negligibly. Furthermore, as presented in Fig. 4, overall, the critical displacement increases with the increasing peak load, thus Fig. 5b exhibits the similar shape as Fig. 5a.

\section{Interface slip and strength}

Aforementioned text presents the load-bearing capacity and its influence factors of the adhesive joint. Most of the experimental results have indicated that the failure of the adhesive joints always occurs due to the failure of the adhesive layer $[2,6,10,28,38,39]$. Accordingly, the load-bearing capacity of the adhesive joint depends on the adhesive layer, which can be equivalent to the interface between the two adherends connected 
a

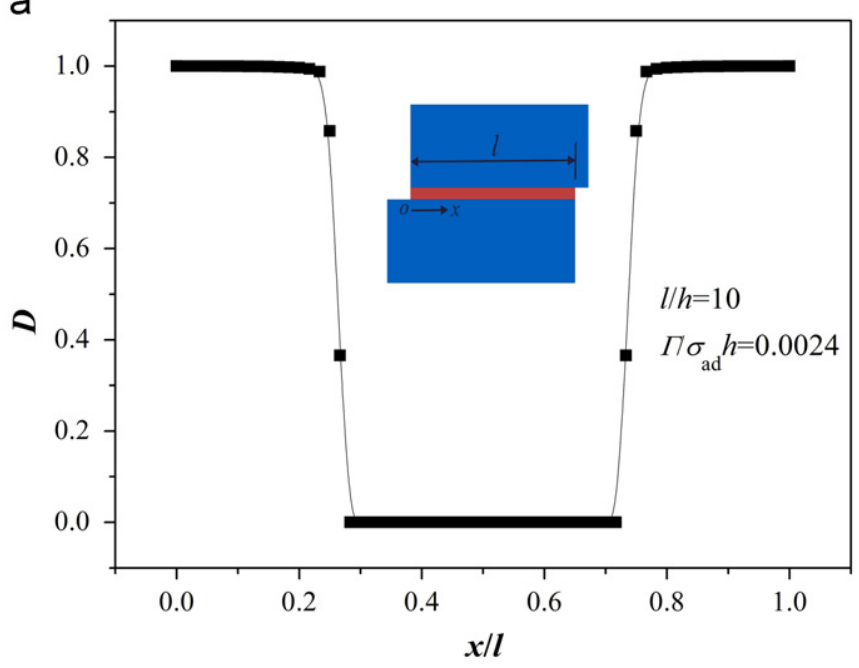

b

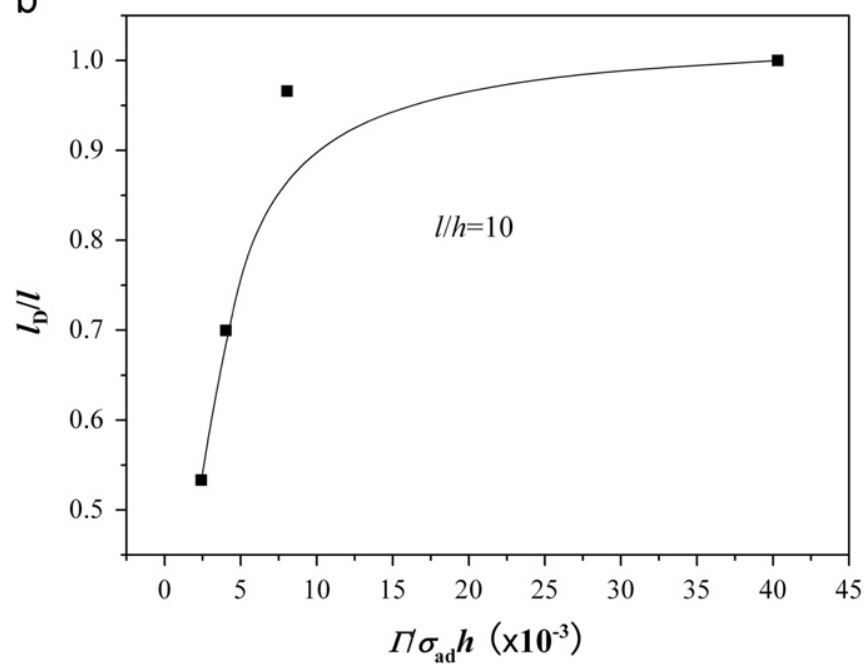

Fig. 9. Considering the case for normalized overlap length of 10, (a) damage distribution of the adhesive layer when the load arrive to the peak for the normalized adhesive fracture energy of 0.0024 and (b) damage level plotted as a function of normalized adhesive fracture energies.

by the joint. The interface behavior is therefore vital for the loadbearing capacity. In this section, we process to perform the interface behavior analyses including the interface stress, slip and strength, also the rotation of the joint and its affect factors are investigated finally.

\subsection{Interface slip}

Due to the stress concentration, both extremities of the adhesive layer (i.e., $x=0$ and $x=l$ shown in Fig. $1 \mathrm{~b}$ ) should be focused on as key points. Furthermore, the interface shear stress has been regarded as the main stress component inducing interface failure during the deformation, the relation between the interface shear stress and interface slip at the extremities of the adhesive is thence considered at the beginning of this section. Here, interface slip denotes the horizontal displacement difference between the top and bottom of the adhesive layer at extremities, which can be expressed by $\delta_{x}=u_{x}^{\text {top }}-u_{x}^{\text {bottom }}$.

Fig. 10a-d plot the normalized interface shear stresses as functions of interface slips for various adhesive fracture energies, considering the cases of four selected overlap lengths. It can be found in the figures there is discrepancy between the curves for the brittle and ductile adhesive layers. Taking Fig. 10b for example, all the curves are similar in the upward stages. However, the discrepancy comes out in the downward stages, which depends on the types of the adhesive layer. In detail, for the cases of brittle adhesive layer with the lower normalized adhesive fracture energies (i.e., $2.42 \times 10^{-3}, 4.03 \times 10^{-3}$ and $8.06 \times 10^{-3}$ ), the curves drop down to zero sharply in the downward stages. By contrast, for the cases of ductile adhesive layer with the higher normalized adhesive fracture energies (i.e., $40.31 \times 10^{-3}, 80.61 \times 10^{-3}$ and $120.92 \times 10^{-3}$ ), after the shear stress reaches peaks, the curves drop down firstly and rise up until to another peaks, then decrease to zero slowly. In other words, there exist valleys in the curves for the cases with higher adhesive fracture energies.

As shown in Fig. 10, the slip corresponding to the shear stress dropping to zero could be defined as the failure slip, which can be plotted as a function of normalized adhesive energies in Fig. 11. The figure presents that the failure slip increases as the adhesive fracture energy is increased. However, it suggests that the effect of overlap length is negligible, for which the failure slip is regarded as a material property of the adhesive and should not depend on the overlap length.

\subsection{Interface stress analysis}

It is interesting to observe from Fig. 10 that valleys exist in the curves for the cases with higher adhesive fracture energies. The reason would be clarified through the interface stress analysis.

In order to perform the interface stress analysis, a case is taken for example, with the selected parameters (i.e., $l / h=6.67$ and $\left.\Gamma / \sigma_{\text {ad }} h=40.31 \times 10^{-3}\right)$. The interface stress analyses at three positions of the adhesive layer are taken into account, which correspond to the mid-point, right and left extremities of the adhesive, with depicted in Fig. 12a-c, respectively. The normalized stresses plotted in Fig. 12a (i.e., case of mid-point), varying with the increasing slip, have noticeable discrepancy in normal and shear directions. The shear stress goes up until to a peak, while the normal stress goes down until to a valley, which means the normal stress in the mid-point of the adhesive layer is compressive stress. Different from the case of the mid-point, the stresses in both extremities of the adhesive layer are positive (see Fig. $12 b$ and $c$ ). It should be noticed the curves in the left extremity are the same as the right extremity due to symmetry. As mentioned in Section 4.1, there exists a valley in the curve for relation between the shear stress and slip. It can be interpreted by the effect of normal stress. In order to present the variation of the total stress during the slip, the effective stress is brought by,

$\Sigma=\sqrt{\left(\frac{\sigma^{n}}{\sigma_{a d}}\right)^{2}+\left(\frac{\sigma^{s}}{\sigma_{a d}}\right)^{2}}$

which is also plotted as a function of the slip in Fig. 12b. It presents the critical displacement corresponding to the peak effective stress is very close to that corresponding to the peak shear stress, which suggests the damage of the extremities in adhesive layer is initiated mainly by the contribution of shear stress. As presented in Fig. 12b, after the effective stress arrive to the peak, it declines smoothly, thus it is understandable that the shear stress arrives to the valley when the normal stress arrives to the peak. It should be noticed that the both the stress components and the effective stress drop to zero simultaneously, with denoting the failure point in the Fig. 12b. The stress analysis shows that the evolution of the interface stresses exhibits mixed-mode, which means both the shear and normal stresses contribute to the failure together. Although one of the stress components would fluctuate with the deformation of the interface, the variation of the total stress makes the interface vulnerable to degradation and failure. 


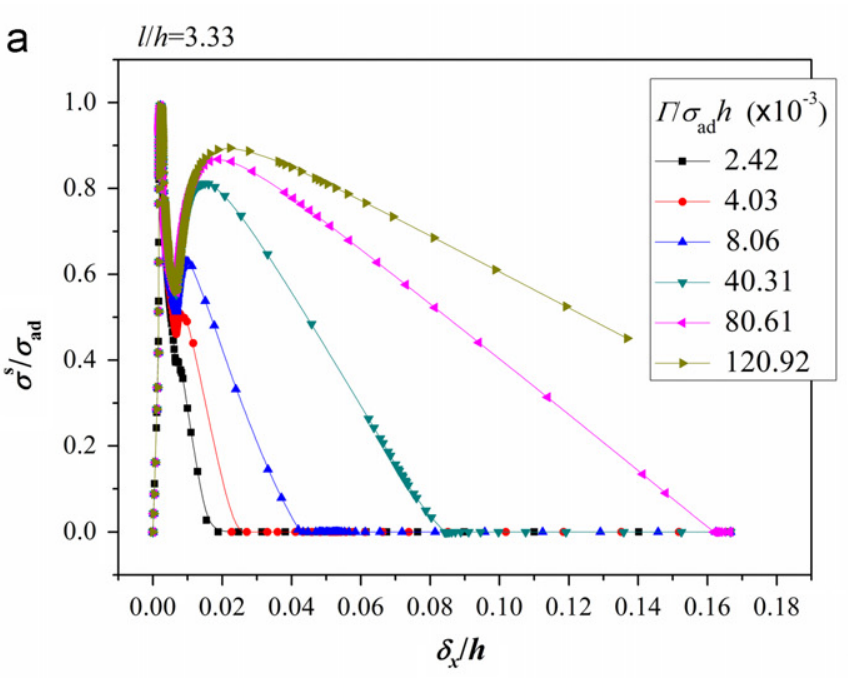

C

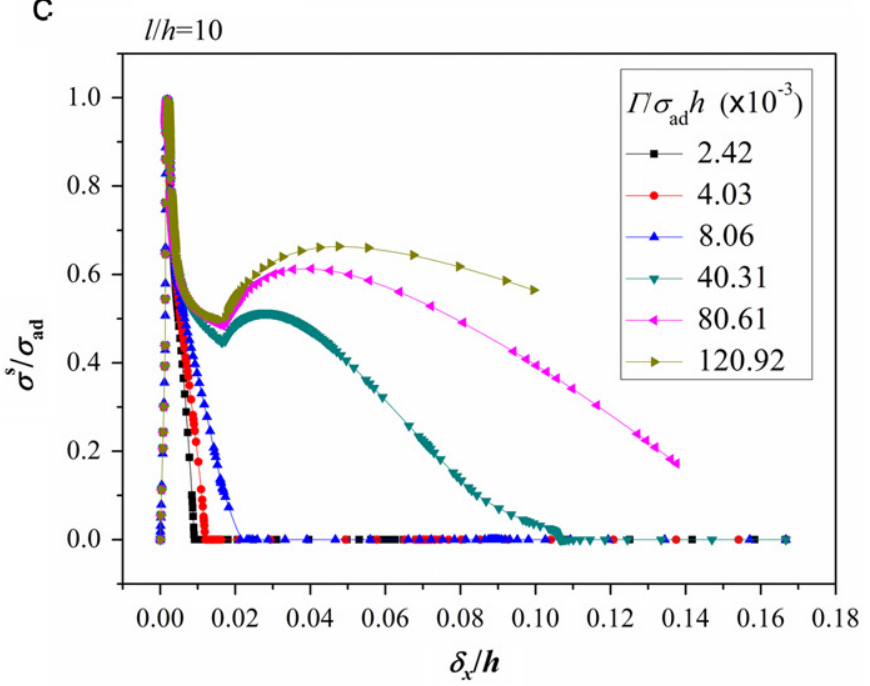

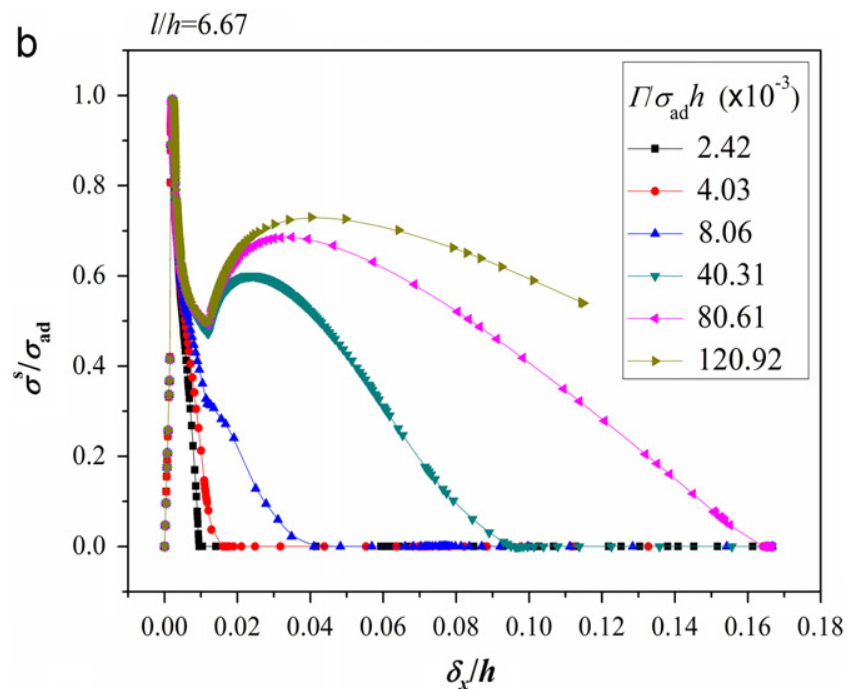

d

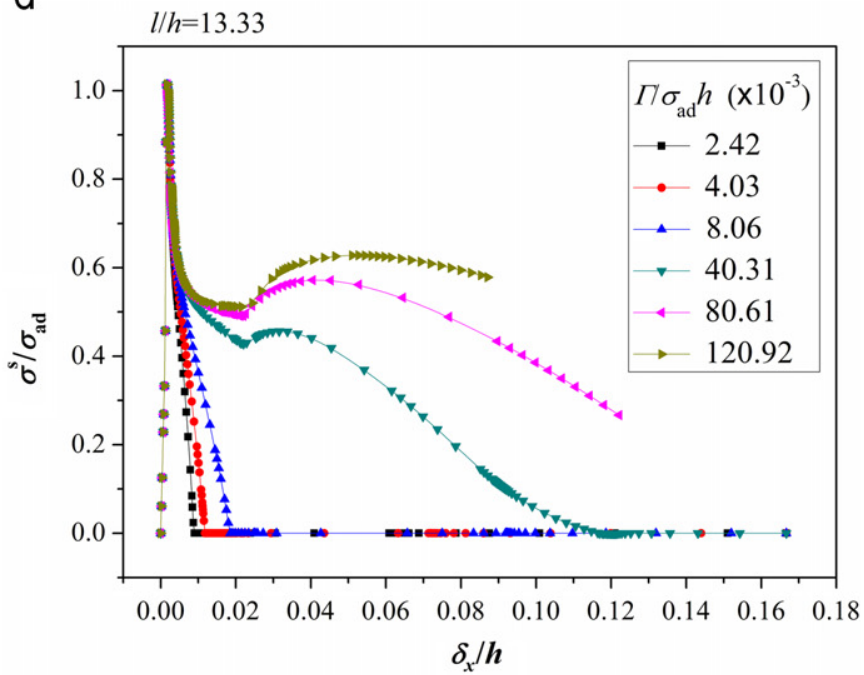

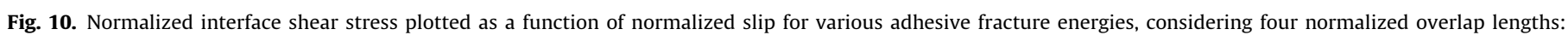
(a) 3.33; (b) 6.67; (c) 10 and (d) 13.33 .

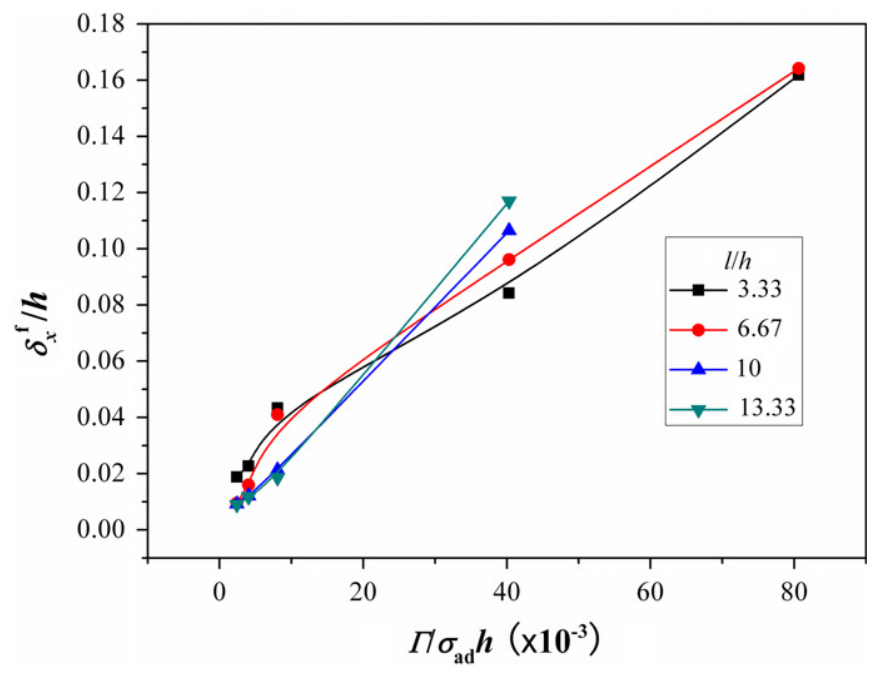

Fig. 11. Influence of the adhesive fracture energy on the failure slip for the selected overlap lengths.

For a purpose of showing the global stress distributions in the adhesive layer, the figures are plotted considering the two situations. Fig. 13a depicts the stress distributions when the shear stress at the extremities arrives to the peak, while Fig. 13b depicts that when the shear stress arrives to the valley (see, Fig. 10a). The shear stress as shown in Fig. 13a have been found to be constant for most portion of the overlap except the areas near the extremities of the adhesive layer, while the normal stress in most portion is smaller than the shear stress except the mid-region. The shear stress component in Fig. 13b attains the peak at the center and decreases towards the extremities. By contrast, at the two extremities of the adhesive layer, the normal stress component attains the maximum value, which is even larger than that of the shear stress component.

\subsection{Rotation analysis}

The stress variations in the adhesive layer are induced partially by the degradation or damage of the adhesive, and partially by the deformation of the joint, which mainly refers to the rotation of it. Due to the effect of the moment, the joint would rotate along the direction of the moment inevitably. To describe the rotation, the rotation angle is defined as the angle between the overlap of the joint and the horizontal direction. It should be noted that the overlap may be bended during the deformation. As a result, the extremity constituting the angle is not straight. To address this problem, the line traveling across the both endpoints (i.e., points 

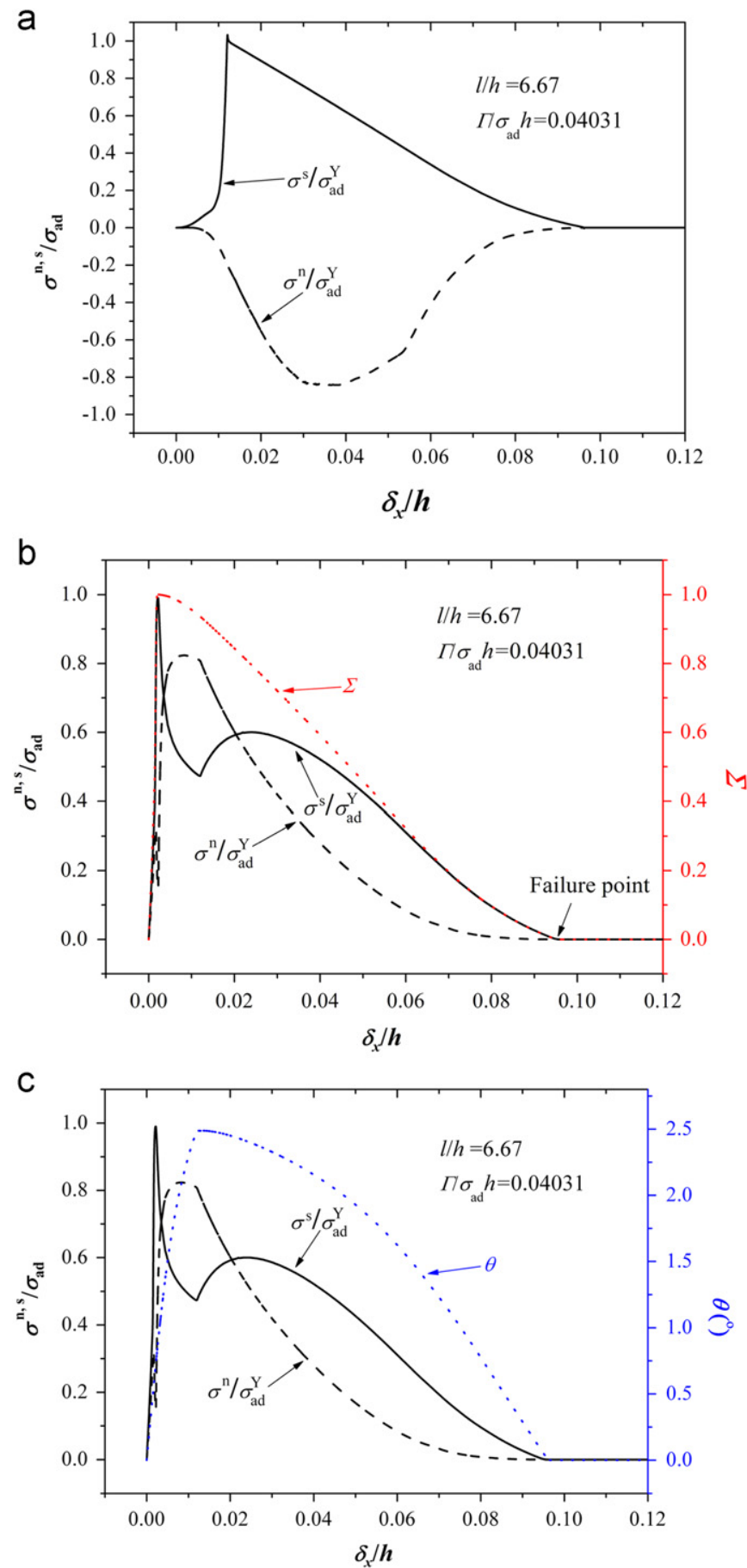

Fig. 12. Interface stresses and rotation angle plotted as a function of normalized slip at selected positions of the adhesive layer: (a) mid-point; (b) right extremity and (c) left extremity.

of the both extremities) of the adhesive layer, instead of the overlap, is used to build the rotation angle.

Considering the case described in Fig. 12c, a curve for the relationship between the rotation angle and slip is also plotted in the figure together with the interface stresses. Obviously, the curve also contains a peak, which is the maximum value during the deformation. It is interesting to find the rotation angle arrive to the peak when the shear stress arrive to a valley. Simultaneously, the normal stress approaches to a peak value. It can be understandable that the relative slip between the adherends is easier when the angle is smaller within the range between $0^{\circ}$
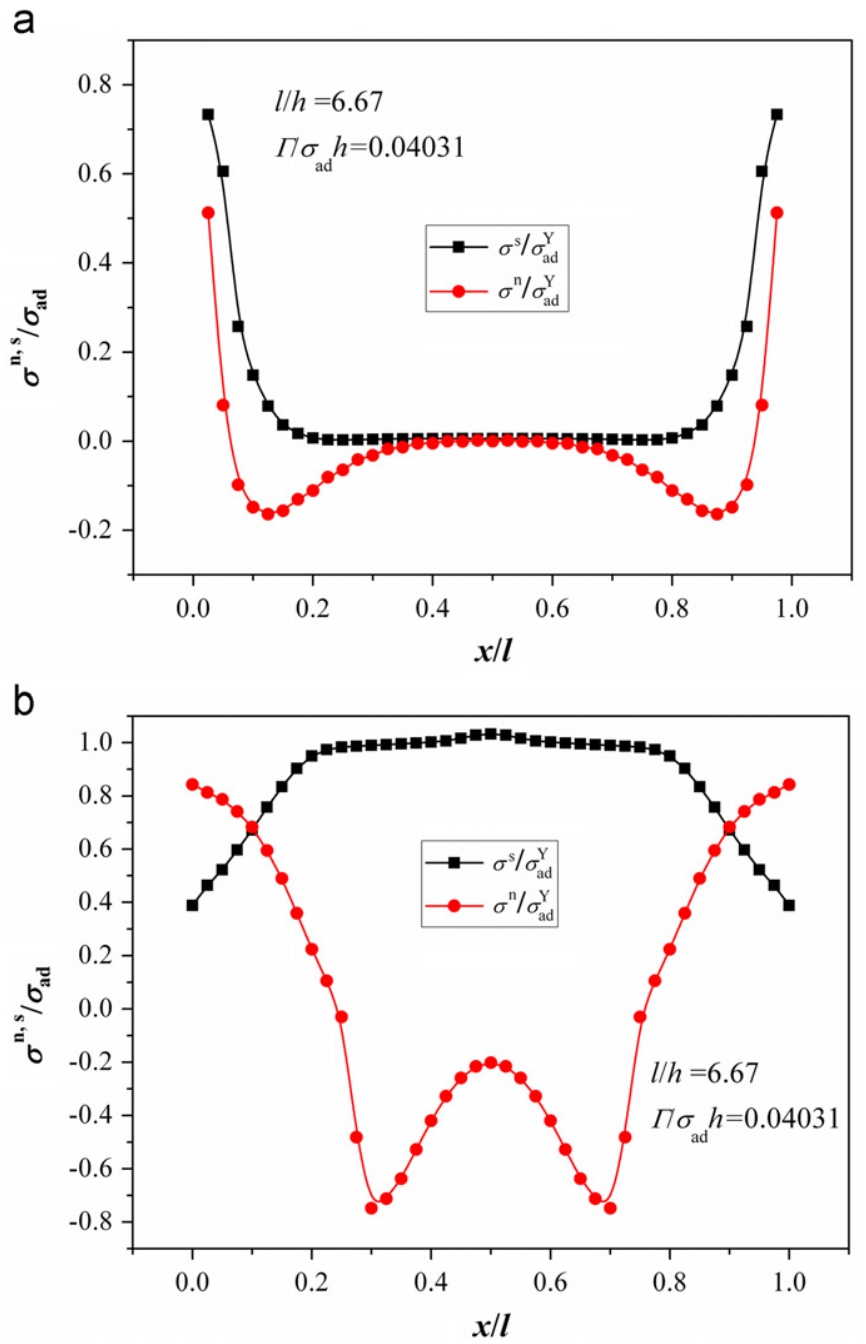

Fig. 13. Interface stress distributions along the overlap for the specified points, (a) when the shear stress at the extremity arrives to peak and (b) when the shear stress at the extremity arrives to valley.

and $90^{\circ}$ by contrast, when the angle is larger within the same range. The relative slip is more difficult while the relative open is easier. Noting that the interface normal and shear stresses are determined by the relative open and slip, respectively, it is reasonable to present the shape of the stress curves in Fig. 12c.

In order to present some factors affecting the rotation angle, Fig. 14 plots the angle as a function of slip for selected adhesive energies, taking four overlap lengths into account. Obviously, the peaks of the angle vary with the selected adhesive energies. It is clear to show the angle peak $\theta_{c}$ as a function of the normalized adhesive fracture energies in Fig. 15. Similar to Fig. 5a, Fig. 15 shows the influence of the adhesive fracture energy on the peak angle, but the increasing trend gets slow down as the adhesive fracture energy is further increased, which implies that a steadystate angle would exist in each curve.

It is interesting that both the Fig. 5a and Fig. 15 are similar in shape, which implies that exist a relation between the loadbearing capacity and the rotation angle. For a purpose of showing the relation, Fig. 16 plots the angle and normalized load as functions of the slip in the same figure for the six selected adhesive fracture energies, shown in Fig. 16a-f, respectively. It is obvious in each figure that the angle-slip and load-slip curves are close in shape. Especially, the critical slips corresponding to the peak angles (denoted by $\delta_{x}^{c, \theta}$ ) seem to be close to the critical 

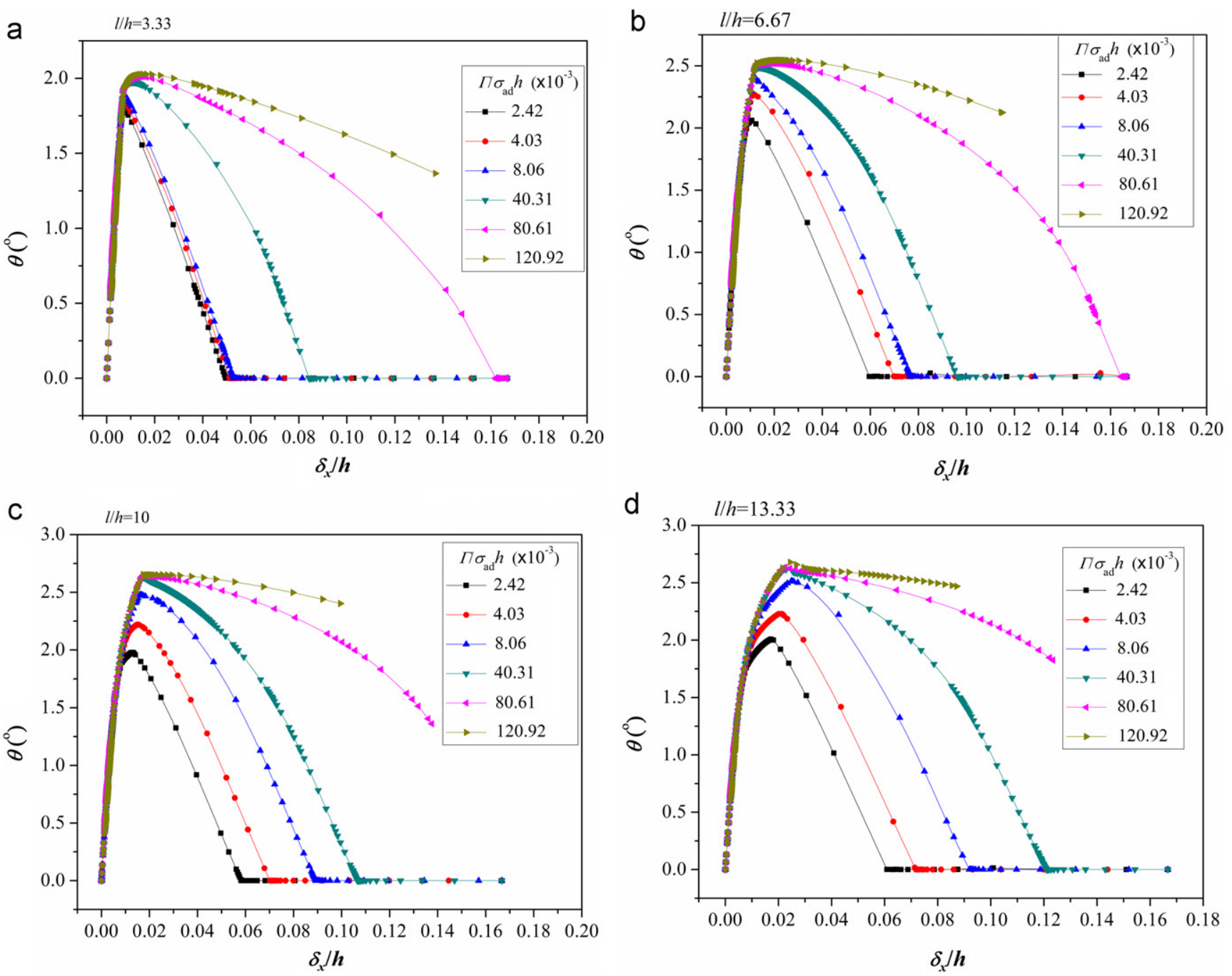

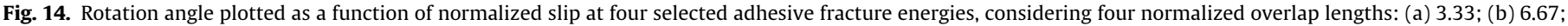
(c) 10 and (d) 13.33 .

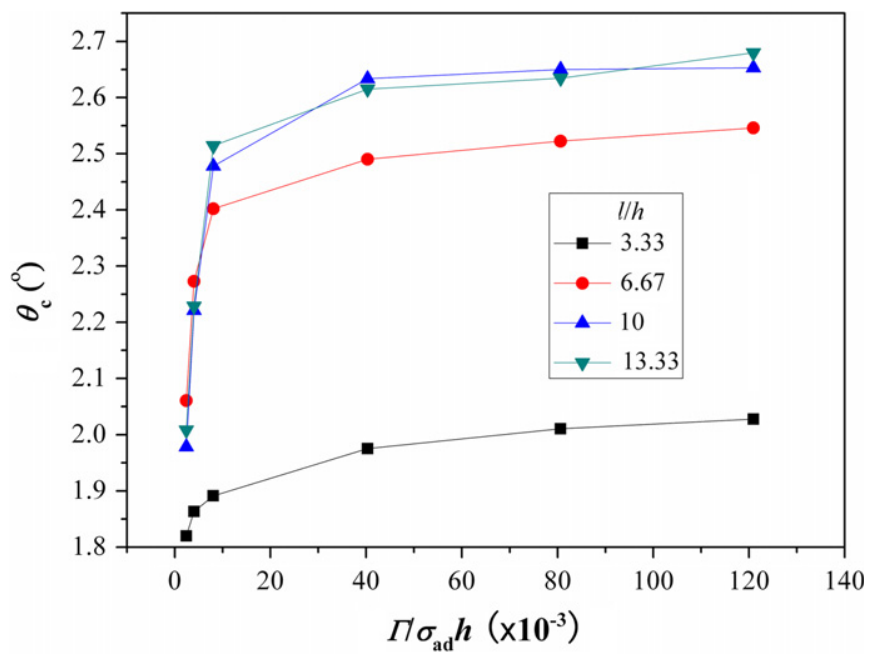

Fig. 15. Influence of normalized adhesive fracture energy on critical rotation angle for selected overlap lengths.

slips corresponding to the peak loads (denoted by $\delta_{x}^{c, F}$ ). It is shown clearly with the comparison of the two critical slips listed in Table 1.
Obtained results suggest the rotation angle relates to the loadbearing capacity. In other words, the peak angle can also be regarded as a critical value of the damage initiation. Different from the damage initiation criterion of the $\mathrm{CZ}$ elements, damage initiation of the joint can be hence determined by the critical values of displacement, slip or rotation angle.

\section{Discussion}

The influences of the adhesive layer properties on the loadbearing capacity of the joints are investigated in the present research. The analysis results show the considerable effect of the adhesive fracture energy on the load-bearing capacity. Previous experimental researches have shown the similar trends that ductile adhesive could enhance the load-bearing capacity substantially $[2,12,39]$, which agrees well with the present simulation. The adhesive separation strengths are assigned a constant value in this paper. However, some researches have pointed out that the adhesive separation strength relates to its fracture toughness or adhesive fracture energy [12]. Thus the further calculation should be performed considering the effect of fracture toughness on the separation strength of the adhesive.

Another significant issue is concerning the influence from the thickness of the adhesive layer. The present study considers the 

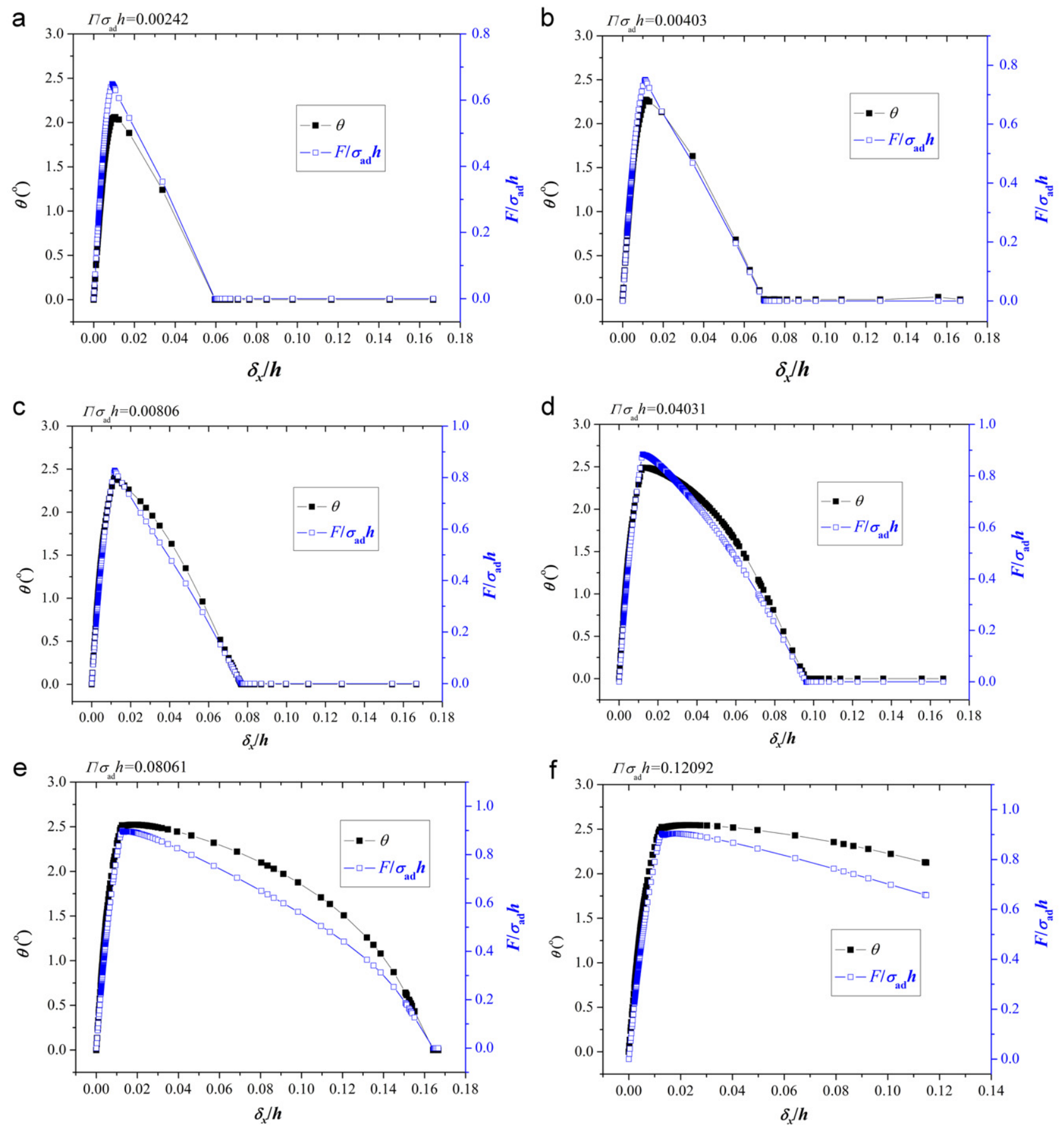

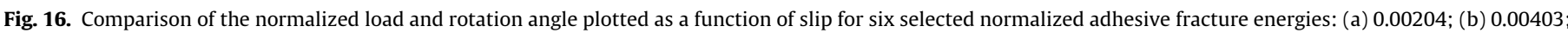
(c) 0.00806 ; (d) 0.04031 ; (e) 0.08061 and (f) 0.12092 .

relationship between the peak load and the adhesive layer thickness, with the results showing that thicker adhesive layer is benefic to enhancing the load-bearing capacity of the joint. Some reported experiments have presented the same result [41] while some other researches have reported the opposite result, which indicates that thinner adhesive layer contributes to improving the load-bearing capacity $[1,2,12]$. This observation may be explained as follows: Firstly, the present model adopts the relatively ductile adhesive, which is able to distribute the load over a larger bonding area [2]. Moreover, the ductility of the adhesive increases as the adhesive thickness is increased in the present simulation. As a result, the failure load increases as the adhesive gets thicker. Secondly, in practice, the amounts of defects such as micro-voids and micro-cracks are larger in the thicker adhesive layer, bonding capacity accordingly [42], whereas the present model doesn't consider the influence of defects. Lastly, the plastic dissipation is more rapid and the interface stress is larger in the thicker adhesive layer, making the adhesive layer vulnerable to failure. Yet the present investigation neglects these influences, just considering the adhesive fracture energy affected by the thickness. To address the deficiencies, more sophisticated models are needed to study the effect of adhesive layer thickness in the future work.

In addition, as mentioned in aforementioned text (see, Section 3.3), numerous literatures and test standards regard the ratio between the peak loads and overlap area as the assessment 
Table 1

Comparison of the critical slips corresponding to the peak load and rotation angle.

\begin{tabular}{cll}
\hline$\Gamma / \sigma_{\mathrm{ad}} h\left(\times 10^{3}\right)$ & $\delta_{x}^{c, F} / h$ & $\delta_{x}^{c, \theta} / h$ \\
\hline 2.42 & 0.01038 & 0.00907 \\
4.03 & 0.01114 & 0.01105 \\
8.06 & 0.01171 & 0.01171 \\
40.31 & 0.01212 & 0.01203 \\
80.61 & 0.01810 & 0.01257 \\
120.92 & 0.02212 & 0.01692 \\
\hline
\end{tabular}

for the interface strength, especially interface shear strength. Whereas the present simulation results indicate the ratio depends on the size of the overlap area (see, Fig. 6b). In other words, the ratio decreases with the increasing overlap length (namely, bonding area). Since the adhesive properties are the material intrinsic parameters, the size-dependent effect should not exhibit obviously. Consequently, further investigations including theoretical and experimental methods are therefore needed to assess the adhesive properties accurately.

Furthermore, the failure mode of the joint is another key issue. In fact, depending on the loading and boundary conditions, there may be three different failure modes as follows: (a) adhesion failure occurs on the interfacial surface between the adherends (i.e., metallic adherends in the present study) and the adhesive layer, (b) cohesion failure occurs in the adhesive layer and (c) delamination damages occur between the surface and the second ply of the adherends [16]. However, in the present model, only the damage of the cohesion failure is carried out and the other two failure modes are not considered. Proper failure criterions should be implemented into models for a purpose of estimating the failure mode in the adhesive bonding systems.

\section{Concluding remarks}

In summary, the finite element method has been used to systematically study the interface failure mechanism and overall strength of single lap joints subjected to tensile loading, focusing on the effects of various system parameters including adhesive fracture energy of the adhesive layer, overlap length and adhesive layer thickness on the load-bearing capability of the joints. The results show that improving the adhesive fracture energy can significantly enhance the load-bearing capability of the joints. It is also demonstrated that the load-bearing capability can be significantly enhanced not only by increasing the overlap length under the condition of larger adhesive fracture energy, but also by increasing the thickness of adhesive layer. A preliminary damage analysis of the adhesive layer is also performed, considering the situations when the loads arrive to the peak values. Besides, the variations of interface stresses are analyzed, and the obtained results show that the evolution of the interface stress exhibits mixed-mode feature. The interface stress distributions depend on both the damage of the adhesive layer and the joint deformation, which can be evaluated by the rotation angle of the overlap. The results show that the rotation angle-slip curves and the load-slip curves present similar in shape, and the critical slips corresponding to the peak rotation angles are very close to that of the loads.

\section{Acknowledgments}

This work was supported by the National Natural Science Foundation of China through Grants 11021262, 10932011 and 90816004,
MOST of China through Grant 2012CB937500. The first author (WX) would like to thank the helpful advice of Dr. Fuqi Qin from Institute of Mechanics, Chinese Academy of Sciences.

\section{References}

[1] Kahraman R, Sunar M, Yilbas B. Influence of adhesive thickness and filler content on the mechanical performance of aluminum single-lap joints bonded with aluminum powder filled epoxy adhesive. J. Mater. Process. Technol. 2008;205:183-9.

[2] da Silva LFM, TNSS Rodrigues, Figueiredo MAV, de Moura MFSF, Chousal JAG. Effect of adhesive type and thickness on the lap shear strength. J. Adhes. 2006:82:1091-115.

[3] Wu ZS, Yuan H, Niu HD. Stress transfer and fracture propagation in different kinds of adhesive joints. J. Eng. Mech. ASCE 2002;128:562-73.

[4] Dai JG, Ueda T, Sato Y. Development of the nonlinear bond stress-slip model of fiber reinforced plastics sheet-concrete interfaces with a simple method. J. Compos. Constr. 2005;9:52-62.

[5] Ascione F. Mechanical behaviour of FRP adhesive joints: A theoretical model. Compos. Part B-Eng. 2009;40:116-24.

[6] Grant LDR, Adams RD, da Silva LFM. Experimental and numerical analysis of single-lap joints for the automotive industry. Int. J. Adhes. Adhes. 2009;29: 405-13.

[7] Grant LDR, Adams RD, da Silva LFM. Effect of the temperature on the strength of adhesively bonded single lap and $\mathrm{T}$ joints for the automotive industry. Int. J. Adhes. Adhes. 2009;29:535-42.

[8] Loureiro AL, da Silva LFM, Sato C, Figueiredo MAV. Comparison of the Mechanical Behaviour Between Stiff and Flexible Adhesive Joints for the Automotive Industry. J. Adhes. 2010;86:765-87.

[9] Higgins A. Adhesive bonding of aircraft structures. Int. J. Adhes. Adhes. 2000;20:367-76.

[10] Pereira AM, Ferreira JM, Antunes FV, Bartolo PJ. Analysis of manufacturing parameters on the shear strength of aluminium adhesive single-lap joints. J. Mater. Process. Technol. 2010;210:610-7.

[11] Sperandio C, Bardon J, Laachachi A, Aubriet H, Ruch D. Influence of plasma surface treatment on bond strength behaviour of an adhesively bonded aluminium-epoxy system. Int. J. Adhes. Adhes. 2010;30:720-8.

[12] da Silva LFM, Carbas RJC, Critchlow GW, Figueiredo MAV, Brown K. Effect of material, geometry, surface treatment and environment on the shear strength of single lap joints. Int. J. Adhes. Adhes. 2009;29:621-32.

[13] You M, Li Z, Zheng XL, Yu S, Li GY, Sun DX. A numerical and experimental study of preformed angle in the lap zone on adhesively bonded steel single lap joint. Int. J. Adhes. Adhes. 2009;29:280-5.

[14] Taib AA, Boukhili R, Achiou S, Boukehili H. Bonded joints with composite adherends. Part II. Finite element analysis of joggle lap joints. Int. J. Adhes. Adhes. 2006;26:237-48

[15] You M, Yan ZM, Zheng XL, Yu HZ, Li Z. A numerical and experimental study of adhesively bonded aluminium single lap joints with an inner chamfer on the adherends. Int. J. Adhes. Adhes. 2008;28:71-6.

[16] Panigrahi SK. Damage Analyses of Adhesively Bonded Single Lap Joints Due to Delaminated FRP Composite Adherends. Appl. Compos. Mater. 2009;16: 211-23.

[17] Nemes O, Lachaud F. Double-lap adhesive bonded-joints assemblies modeling. Int. J. Adhes. Adhes. 2010;30:288-97.

[18] Campilho RDSG, de Moura MFSF, Domingues JJMS. Modelling single and double-lap repairs on composite materials. Composites Sci. Technol. 2005;65:1948-58.

[19] da Silva LFM, das Neves PJC, Adams RD, Spelt JK. Analytical models of adhesively bonded joints-Part I: Literature survey. Int. J. Adhes. Adhes. 2009;29:319-30

[20] Luo QT, Tong LY. Analytical solutions for nonlinear analysis of composite single-lap adhesive joints. Int. J. Adhes. Adhes. 2009;29:144-54.

[21] Tong L. Bond strength for adhesive-bonded single-lap joints. Acta Mech. 1996;117:101-13.

[22] Yuan H, Chen JF, Teng JG, Lu XZ. Interfacial stress analysis of a thin plate bonded to a rigid substrate and subjected to inclined loading. Int. J. Solids Struct. 2007;44:5247-71.

[23] Olia M, Rossettos JN. Analysis of adhesively bonded joints with gaps subjected to bending. Int. J. Solids Struct. 1996;33:2681-93.

[24] Lang TP, Mallick PK. The effect of recessing on the stresses in adhesively bonded single-lap joints. Int. J. Adhes. Adhes. 1999;19:257-71.

[25] You M, Yan ZM, Zheng XL, Yu HZ, Li Z. A numerical and experimental study of gap length on adhesively bonded aluminum double-lap joint. Int. J. Adhes. Adhes. 2007;27:696-702.

[26] Lee DB, Ikeda T, Miyazaki N, Choi NS. Effect of bond thickness on fracture toughness of adhesive joints. J. Eng. Mater. Technol. 2004;126:14-8.

[27] Pardoen T, Ferracin T, Landis CM, Delannay F. Constraint effects in adhesive joint fracture. J. Mech. Phys. Solids 2005;53:1951-83.

[28] Rudawska A. Adhesive joint strength of hybrid assemblies: Titanium sheetcomposites and aluminium sheet-composites-Experimental and numerical verification. Int. J. Adhes. Adhes. 2010;30:574-82.

[29] Chandra N, Li H, Shet C, Ghonem H. Some issues in the application of cohesive zone models for metal-ceramic interfaces. Int. J. Solids Struct. 2002;39: 2827-55. 
[30] Freund LB, Suresh S. Thin Film Materials: Stress, Defect Formation and Surface Evolution. Cambridge: Cambridge University Press; 2003.

[31] Ghosh S, Ling Y, Majumdar B, Kim R. Interfacial debonding analysis in multiple fiber reinforced composites. Mech. Mater. 2000;32:561-91.

[32] Li H, Chandra N. Analysis of crack growth and crack-tip plasticity in ductile materials using cohesive zone models. Int. J. Plasticity 2003;19:849-82.

[33] Balzani C, Wagner W. An interface element for the simulation of delamination in unidirectional fiber-reinforced composite laminates. Eng. Fracture Mech. 2008;75:2597-615.

[34] de Moura MFSF, RDSG Campilho, JPM Goncalves. Mixed-Mode Cohesive Damage Model Applied to the Simulation of the Mechanical Behaviour of Laminated Composite Adhesive Joints. J. Adhes. Sci. Technol. 2009;23: 1477-91.

[35] Moura MFSF De, JPM Goncalves, JAG Chousal, RDSG Campilho. Cohesive and continuum mixed-mode damage models applied to the simulation of the mechanical behaviour of bonded joints. Int. J. Adhes. Adhes. 2008;28:419-26.

[36] Banea MD, Silva LFM. Mechanical Characterization of Flexible Adhesives. J. Adhes. 2009;85:261-85.
[37] de Morais AB, Pereira AB, Teixeira JP, Cavaleiro NC. Strength of epoxy adhesive-bonded stainless-steel joints. Int. J. Adhes. Adhes. 2007;27:679-86.

[38] Lucić M, Stoić A, Kopač J. Investigation of aluminum single lap adhesively bonded joints. Journal of Achievements in Materials and Manufacturing Engineering 2006;15:79-87.

[39] da Silva LFM, Critchlow GW, Figueiredo MAV. Parametric Study of Adhesively Bonded Single Lap Joints by the Taguchi Method. J. Adhes Sci. Technol. 2008;22:1477-94.

[40] Wei YG, Zhao HF. Peeling experiments of ductile thin films along ceramic substrates - Critical assessment of analytical models. Int. J. Solids Struct. 2008;45:3779-92.

[41] Spelt JK, Azari S, Papini M. Effect of adhesive thickness on fatigue and fracture of toughened epoxy joints-Part I: Experiments. Eng. Fracture Mech 2011;78:153-62.

[42] Xu W, Wei YG. Strength analysis of metallic bonded joints containing defects. Computational Materials Science 2012;53:444-50. 